\title{
Chemotherapeutic potential of curcumin-bearing microcells against hepatocellular carcinoma in model animals
}

This article was published in the following Dove Press journal:

International Journal of Nanomedicine

3 March 2014

Number of times this article has been viewed

\author{
Mohammad Farazuddin' \\ Bhavyata Dua ${ }^{2}$ \\ Qamar Zia' \\ Aijaz Ahmad Khan ${ }^{3}$ \\ Beenu Joshi \\ Mohammad Owais' \\ 'Interdisciplinary Biotechnology Unit, \\ Aligarh Muslim University, Aligarh, \\ ${ }^{2}$ Immunology Division, National \\ JALMA Institute for Leprosy and \\ Other Mycobacterial Diseases (NJIL), \\ Agra, ${ }^{3}$ Department of Anatomy, \\ Jawaharlal Nehru Medical College, \\ Aligarh Muslim University, Aligarh, \\ India
}

Correspondence: Mohammad Owais Interdisciplinary Biotechnology Unit, Aligarh Muslim University, Aligarh 202002, India

$\mathrm{Tel}+9|57| 2720388$

Fax +91 57| 2721776

Email owais_lakhnawi@yahoo.com

\begin{abstract}
Curcumin (diferuloylmethane) is found in large quantities in the roots of Curcuma longa. It possesses strong antioxidant and anti-inflammatory properties, and inhibits chemically-induced carcinogenesis in the skin, forestomach, colon, and liver. Unfortunately, the poor bioavailability and hydrophobicity of curcumin pose a major hurdle to its use as a potent anticancer agent. To circumvent some of these problems, we developed a novel, dual-core microcell formulation of curcumin. The encapsulation of curcumin in microcells increases its solubility and bioavailability, and facilitates slow release kinetics over extended periods. Besides being safe, these formulations do not bear any toxicity constraints, as revealed by in vitro and in vivo studies. Histopathological analysis revealed that curcumin-bearing microcells helped in regression of hepatocellular carcinoma and the maintenance of cellular architecture in liver tissue. Free curcumin had a very mild effect on cancer suppression. Empty (sham) microcells and microparticles failed to inhibit cancer cells. The novel curcumin formulation was found to suppress hepatocellular carcinoma efficiently in Swiss albino mice.
\end{abstract}

Keywords: diferuloylmethane, carcinogenesis, microparticle, nanocells, cancer, Curcuma longa

\section{Introduction}

Hepatocellular carcinoma (HCC) is believed to be the fifth most common solid tumor worldwide, and is one of the leading causes of cancer-related death. ${ }^{1}$ Because it is generally diagnosed at an advanced stage, available chemotherapy modules fail to cure HCC. ${ }^{2}$ Moreover, available chemotherapeutic agents against cancer suffer from intrinsic toxicity issues when used in clinical settings.

Recent studies on tumor-inhibiting compounds of plant origin have established alternate modes for cancer chemoprevention. Different phytochemicals, including dietary agents and nutrients, have been found to be effective against various types of cancer. Active substances include vitamin, flavone, and phenolic derivatives, sulfur-containing compounds, isothiocyanates, etc. Curcumin (diferuloylmethane), found in abundance in the roots of Curcuma longa (Figure 1) ${ }^{3}$ has been used as a spice and coloring agent in India and the People's Republic of China for centuries. It possesses antioxidant and anti-inflammatory properties, and inhibits chemically-induced carcinogenesis in the skin, forestomach, colon, and liver. ${ }^{4-8}$

Despite the high efficacy of phytochemicals in general, toxicity, and other side effects, manifest when they are administered at high doses. Moreover, non-targeted accumulation, fast elimination, and poor solubility are among major hurdles in their use in clinical settings. Although curcumin has been reported not to possess any toxicity, even at high dosage, its poor bioavailability makes it not useful for the treat- 


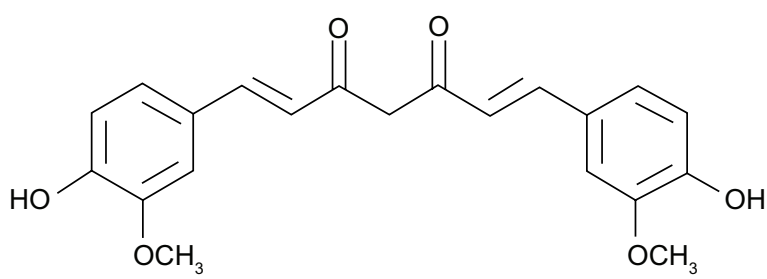

Figure I Chemical structure of curcumin.

ment of cancer. There have been intensive research efforts to overcome the constraints of solubility and bioavailability. With the aim of increasing bioavailability, we developed various microparticle-based formulations of curcumin. Because the selection of polymers for use in developing microparticles plays a crucial role in regulating their pharmacokinetic properties, we evaluated a range of polymers with desirable properties. The main criteria in this regard focused on entrapment efficiency and sustained drug release over extended periods. We chose poly(lactic-co-glycolic acid) (PLGA) and phosphatidylcholine (PC) for developing our dual-core delivery system. PLGA is a nonenzymatically-degradable polymer. We used PLGA, with a 50:50 molar ratio of lactide to glycolide, for the preparation of microparticles. We further co-entrapped curcumin-bearing PLGA microparticles in PC liposomes (microcells), to control release of the entrapped molecules in a regulated manner. Both of the encapsulation materials have the advantages of being biodegradable and nontoxic,, 10 and have been used widely for the treatment of infectious diseases and cancer. ${ }^{11-13}$

We studied the toxicity and biodistribution of a microcellbased dual-core system for delivery of curcumin to various vital organs. Finally, we assessed the anticancer efficacy of curcumin against diethylnitrosamine-(DEN) induced HCC in model animals.

\section{Materials and methods}

Curcumin, egg PC, cholesterol, PLGA, and polyvinyl alcohol (PVA) were procured from Sigma-Aldrich (St Louis, MO, USA). Anti-p53 (wild type), anti-Bax, anti-B-cell lymphoma2(Bcl-2), and anti-beta-actin antibodies were purchased from BD Biosciences (San Jose, CA, USA). Liver and kidney function tests were performed using kits from Span Diagnostics Ltd. (Gujarat, India). Other chemicals used were of analytical grade, procured locally.

\section{Preparation of curcumin-bearing PLGA microparticles}

Microparticles were prepared using the oil-in-water $(\mathrm{o} / \mathrm{w})$ emulsion solvent evaporation technique, according to published protocols standardized in our laboratory. ${ }^{14,15}$ Briefly, curcumin (30 mg dissolved in a minimum volume of dimethyl sulfoxide [DMSO]) was mixed with PLGA solution (190 mg PLGA dissolved in $0.5 \mathrm{~mL}$ dichloromethane), then sonicated in a bath sonicator (Power Sonic 405, Hwashin Technology Co., Seoul, South Korea) to obtain an emulsion. Subsequently, the emulsion was added to $10 \%$ PVA $(50 \mathrm{~mL})$ and homogenized using a Silverson L4RT Homogenizer (Silverson Machines, East Longmeadow, MA, USA). The resulting $\mathrm{o} / \mathrm{W}$ emulsion was then stirred, at ambient temperature $\left(25^{\circ} \mathrm{C}\right)$, for 18 hours, to allow solvent evaporation, leading to curcumin-loaded microparticle formation. The microparticles were centrifuged at $9,168 \times \mathrm{g}$ for 10 minutes, then washed with phosphate buffered saline (PBS) $(0.15 \mathrm{M}$ sodium chloride, containing $20 \mathrm{mM}$ sodium phosphate; $\mathrm{pH}$ 7.4), to remove non-entrapped drug. The microparticlebased formulation was lyophilized, and then stored at $4^{\circ} \mathrm{C}$ until use.

\section{Preparation of PLGA microparticle- bearing microcells}

Curcumin-bearing microparticles were further co-entrapped in PC liposomes using a freeze-thaw method. Briefly, PC liposomes were prepared from egg PC $(49 \mu \mathrm{M})$ and cholesterol $(21 \mu \mathrm{M})$ using a published method, with some modifications standardized in our laboratory. ${ }^{16}$ Curcumin-loaded PLGA microparticles were centrifuged at 2,000 $\times \mathrm{g}$ for 5 minutes. The supernatant, with small-sized microparticles, was then separated. The small-sized, microparticle fraction was then mixed with empty PC liposomes, and subjected to several cycles of freeze and thaw. The microcell-bearing suspension was then subjected to sonication for 5 minutes, in a water bath sonicator. The suspension was then centrifuged at 5,000 $\times \mathrm{g}$ for 5 minutes. After centrifugation, the supernatant, consisting of empty liposomes, was discarded; the middle layer, having only curcumin-loaded microparticles, was separated from the empty microcells. Microcells were characterized for their size and surface properties.

\section{Entrapment efficiency of curcumin in PLGA microparticles and microcells}

The entrapment efficiency of curcumin in PLGA microparticles and microcells was measured by dissolving $10 \mathrm{mg}$ of freeze-dried formulations in $1.0 \mathrm{~mL}$ of $0.1 \mathrm{M}$ methanolic sodium hydroxide. ${ }^{14,15}$ This solution was vortexed, then incubated at $37^{\circ} \mathrm{C}$ for 1 hour. After incubation, the solution was centrifuged at $9,168 \times \mathrm{g}$ at $25^{\circ} \mathrm{C}$ for 10 minutes. The supernatant was then examined for its curcumin content, using a 
high-performance liquid chromatography (HPLC) method, according to a published procedure ${ }^{17}$ Briefly, an aliquot (100 $\mu \mathrm{L}$ ) of supernatant was mixed with $900 \mu \mathrm{L}$ of methanol. Aliquots of the resultant homogenate solution were analyzed by reversed-phase HPLC, using a Symmetry ${ }^{\circledR}$ C-18 Column (3.9 mm $\times 150 \mathrm{~mm}$ ) (Waters Corp, Milford, MA, USA). The solvent system consisted of isocratic grade acetonitrile, methanol, and water in a volumetric ratio of 55:35:10. A standard curve for the drug was plotted at $425 \mathrm{~nm}$, by determining the area under the curve corresponding to a known (increasing) quantity of the drug.

\section{Microcells-mediated transfer of entrapped calcein}

To track the fate of the dual-core delivery system, in order to substantiate its carrier potential, we studied the interaction of microcells with cancer cell lines. Briefly, a $200 \mathrm{mM}$ solution of calcein (a fluorescent marker) was loaded into microcells, as discussed previously. The liver cancer cell line HepG2 was cultured on glass coverslips, with Roswell Park Memorial Institute (RPMI) medium, in a carbon dioxide incubator $\left(5 \% \mathrm{CO}_{2}\right)$ at $37^{\circ} \mathrm{C}$ overnight. Next morning, the cells were washed thoroughly with Hank's Buffered Salt Solution, then incubated with calcein-loaded microcells for 30 minutes at $37^{\circ} \mathrm{C}$. The population of microcells that had not interacted was removed by thorough washing. The remaining cells were then mounted on coverslips and covered in glycerol. Cells were observed using a fluorescence microscope (Karl Zeiss AG, Oberkochen, Germany) with an I3 filter. Phase contrast and fluorescent micrographs were recorded.

\section{In vitro release kinetics of curcumin from PLGA microparticles and microcells}

For PLGA microparticles and microcells, multiple samples of given formulations were weighed and dispensed into various microvials. Final volumes were made up to $1.0 \mathrm{~mL}$ in each vial, using $20 \mathrm{mM}$ sterile phosphate buffer. The vials were then incubated at $37^{\circ} \mathrm{C}$. After centrifugation at $9,168 \times \mathrm{g}$ for 10 minutes, an aliquot of $100 \mu \mathrm{L}$ was removed from each vial and exchanged with fresh buffer (as at every time point thereafter). The content of curcumin was determined as described previously. ${ }^{17}$ Concentrations of released curcumin were calculated from the standard curve of the drug, plotted in presence of $20 \mathrm{mM}$ phosphate buffer.

\section{Animals}

For in vivo studies, female Swiss albino mice (weight: $20 \pm 2 \mathrm{~g}$ ) were obtained from our institution's animal housing facility (Interdisciplinary Biotechnology Unit [AMU, Aligarh, India] Animal House Facility), and were kept on a standard pellet diet (Hindustan Unilever, Mumbai, India), with water, ad libitum. Animals were checked twice daily for mortality and morbidity, prior to the commencement of the study. Only healthy animals were used in the in vivo experiments. The techniques used for mouse handling, bleeding, injection, and sacrifice were performed in strict accordance with guidelines of the Government of India's Committee for the Purpose of Control and Supervision of Experiments on Animals (CPCSEA). The experimental protocols used in the in vivo studies were approved by our Institutional Ethics Committee (CPCSEA 332).

\section{Toxicity tests for curcumin formulations}

A new drug formulation must be tested for any inherent toxicity before it can be used for efficacy studies. To account for this, toxicity issues were assessed both in vitro and in vivo. Preliminary acute drug toxicity was tested through an in vitro erythrocyte lysis test, wherein hemoglobin, which is released as a result of leakage, or membrane disruption, caused by exposure to therapeutic dosages of the drug, is measured. ${ }^{18}$ Briefly, fresh blood was obtained from a healthy rabbit, collected in anticoagulant solution (ethylenediaminetetraacetic acid), then centrifuged at $1,500 \times \mathrm{g}$ for 10 minutes at $4^{\circ} \mathrm{C}$. Buffy coat and plasma were discarded, and the remaining erythrocytes were washed three times with PBS ( $\mathrm{pH} 7.4$ ). The washed erythrocytes were diluted with isotonic buffer (10 mM PBS), and 50\% hematocrit was prepared. To study the extent of hemolysis, the red blood cell (RBC) suspension was incubated with $1.0 \mathrm{~mL}$ of free-form, microcell-, and microparticle-encapsulated curcumin $(10 \mathrm{mg} / \mathrm{mL})$ at $37^{\circ} \mathrm{C}$ for 1 hour. Free-form curcumin $(10 \times$ therapeutic dose) was dissolved in $50 \mu \mathrm{L}$ of DMSO, and the final volume made up to $1.0 \mathrm{~mL}$ with PBS (final concentration: 5\% DMSO). After 1 hour, the reaction mixture was centrifuged at $1,500 \times \mathrm{g}$. Supernatant was collected and analyzed for released hemoglobin, using ultraviolet (UV)-visible spectroscopy $\left(\lambda_{\text {max }}=576 \mathrm{~nm}\right)$. Percentage hemolysis was determined using the following formula:

$$
[(\mathrm{AbsT}-\mathrm{AbsC}) / \mathrm{Abs} 100 \%-\mathrm{AbsC})] \times 100
$$

where AbsT is the absorbance of the supernatant from samples incubated with the drug, $\mathrm{AbsC}$ is the absorbance of the supernatant from controls (PBS), and Abs100\% is the absorbance of the supernatant of controls incubated in 
the presence of $1 \%$ Triton $^{\circledR} \mathrm{X}-100$ (Sigma-Aldrich), which causes complete lysis of RBCs (total hemolysis).

Hepatic and renal toxicities were monitored by applying a multi-dose regimen (three doses in total, applied on alternate days) to determine biochemical profiles of serum creatinine and alkaline phosphatase (ALP). Blood was collected from a retro-orbital puncture from each mouse after administration of last dose. The blood was allowed to clot at room temperature, before serum was separated for determining levels of creatinine and ALP, as per the guides provided by the manufacturers.

\section{MTT assay}

The effects of curcumin-loaded microcells and PLGA microparticles on the viability of HepG2 cells were determined by MTT assay. In each experiment, $100 \mu \mathrm{L}$ aliquots of growth medium, containing exponentially growing cells, were placed into 96 -well plates, at $1.0 \times 10^{5}$ cells per well, then incubated for 24 hours. Subsequently, HepG2 cells were incubated with various formulations of curcumin (at concentrations of $0,4,6,8,10,12,16$, and $20 \mu \mathrm{M}$, with eight wells per concentration). After 48 hours of incubation, MTT solution $(5 \mathrm{mg} / \mathrm{mL})$ was added to each well. After 4 hours incubation, precipitate formazan was dissolved in $100 \mu \mathrm{L}$ DMSO, and absorbance was measured using an enzyme-linked immunosorbent assay (ELISA) reader (Thermo Molecular Devices Co, Union City, NJ, USA), at $570 \mathrm{~nm}$. Cell viability ratio was calculated using the following equation:

$$
\text { Cell viability ratio }(\%)=\mathrm{OD}_{\text {treated }} / \mathrm{OD}_{\text {control }} \times 100 \%
$$

$\mathrm{IC}_{50}$ (the concentration reducing cell viability by $50 \%$ ) was calculated from the concentration-response curve, and expressed as $\mu \mathrm{M}$.

\section{In vivo biodistribution studies of curcumin}

In vivo biodistribution studies were carried out using Swiss albino mice, weighing $20 \pm 2 \mathrm{~g}$. The studies followed three experimental groups of ten animals each.

- Group I: free-form curcumin

- Group II: PLGA microparticle-encapsulated curcumin

- Group III: curcumin-bearing microcells.

Various curcumin-bearing formulations (as well as freeform curcumin) were injected intraperitoneally, at a dose of $200 \mathrm{mg} / \mathrm{kg}$. Only single injections were administered. At different time points, blood was collected, via retro-orbital puncture, and the animals were sacrificed, for quantification of the drug in various vital organs. The vital organs (liver, kidney, and spleen) were removed aseptically, and then washed with RPMI medium. Organs were thoroughly rinsed, dried with tissue paper, and weighed. Next, each organ was homogenized, using HPLC buffer, and centrifuged at 9,168 $\times$ g. Supernatant was collected for HPLC examination, and curcumin content was calculated from the standard plot for each organ. For determination of curcumin in systemic circulation, blood was centrifuged at $1,000 \times \mathrm{g}$ for 10 minutes, and serum was collected. Serum proteins were precipitated with HPLC buffer, and then centrifuged at $9,168 \times \mathrm{g}$ for 10 minutes. Supernatant was then collected, and examined for curcumin content.

\section{Induction of liver cancer by diethylnitrosamine}

Liver cancer in experimental models was induced, following a method described elsewhere, which has been standardized in our laboratory. ${ }^{19}$ Briefly, a dose of $2.4 \mathrm{mg}$ DEN per animal was delivered by intraperitoneal injection, and animals were quarantined for 40 days. After this incubation period, cancer establishment was determined by assessing liver function enzymes in three representative animals.

\section{Assessment of anticancer efficacy}

The efficacy of curcumin-based formulations was assessed by examining various parameters, including liver enzymes, liver histology, Western blot profile of apoptotic molecules, and percentage survival of animals. Curcumin was used at a dose of $50 \mathrm{mg} / \mathrm{kg}$ body weight, as this dose had already been shown to reduce tumor incidence and increase survival in the ascites mouse model. ${ }^{20}$ All formulations of curcumin were delivered intraperitoneally for a period of 10 days after tumor induction. The animals were kept for 30 days, to observe the effects of the formulations. Animals were divided into the following experimental groups, each containing ten animals.

- Group I: healthy control (no DEN treatment)

- Group II: untreated control (DEN treatment only)

- Group III: sham PLGA microparticles

- Group IV: sham microcells

- Group V: free curcumin $(50 \mathrm{mg} / \mathrm{kg})$

- Group VI: curcumin-loaded PLGA microparticles $(50 \mathrm{mg} / \mathrm{kg})$

- Group VII: curcumin-bearing microcells (50 mg/kg).

\section{Assessment of liver enzymes}

The induction of cancer through exposure to DEN is accompanied by upregulation of liver enzyme function. ${ }^{21}$ Liver function test (LFT) parameters (ALP, aspartate aminotransferase 
[ASP], and gamma-glutamyltransferase [GGT]) offer a direct assessment of the efficacy of various curcumin-based formulations in the treatment of liver cancer.

\section{TNF- $\alpha$ expression}

The tumor necrosis factor alpha cytokine (TNF- $\alpha)$ is a member of the TNF superfamily, and plays an important role in apoptosis of cancerous cells. ${ }^{22}$ TNF- $\alpha$ concentration was measured in serum samples from treatment groups using an ELISA method, following a published protocol. ${ }^{23}$ Briefly, $50 \mu \mathrm{L}$ of purified "capture" antibody were coated on polystyrene microtiter plates, at $4^{\circ} \mathrm{C}$ in a carbonate buffer (pH: 9.4). After overnight incubation, plates were washed five times in PBS with Tween 20 (PBST), then blocked with 5\% w/v non fat dry milk. After 1 hour of incubation at $37^{\circ} \mathrm{C}$, plates were washed with PBST and incubated with $50 \mu \mathrm{L}$ of sample, for cytokine detection. After 2 hours of incubation at $37^{\circ} \mathrm{C}$, plates were washed, and then coated with biotinylated anti-mouse TNF- $\alpha$ (the "detection" antibody). Plates were then washed three times with PBST, and $100 \mu \mathrm{L}$ of horseradish peroxidase (HRP) streptavidin conjugate (streptavidin HRP) was added. Plates were incubated for 30 minutes at room temperature $\left(25^{\circ} \mathrm{C}\right)$, then washed three times with PBST. Finally, a colored complex was developed using tetramethylbenzidine. Absorbance was read at $450 \mathrm{~nm}$, using a microtiter plate reader. A standard curve was plotted, using various known concentrations of recombinant TNF- $\alpha$.

\section{Preparation of nuclear fraction}

Liver tissue was removed from experimental mice aseptically and placed on ice. Tissue samples were homogenized in the presence of a protease inhibitor cocktail, then a nuclear fraction was prepared, according to a method published elsewhere. ${ }^{24}$

\section{Western blotting}

The nuclear fraction was analyzed for the presence of various apoptotic molecules, using the Western blotting method. ${ }^{25}$ Briefly, the protein content of homogenate was estimated using the routine method, using bovine serum albumin as the standard. ${ }^{26}$ Proteins (30 $\mu \mathrm{g}$ per well) were resolved, under non-denaturing conditions, using polyacrylamide gel electrophoresis, then electroblotted onto nitrocellulose membranes. The blots were blocked overnight with 5\% nonfat dry milk, then probed with appropriate antibodies, at the dilutions recommended by the suppliers. To quantify equal loading, membranes were reprobed with $\alpha$-tubulin antibody. The intensity of the band was quantitated using image analysis software and a gel image documentation system.

\section{Statistical analysis}

All graphs were plotted using Microsoft Office Excel 2007 software (Microsoft Corporation, Redmond, WA, USA). Analyses were performed using SigmaPlot version 11.0 (Systat Software Inc., San Jose, CA, USA). Kaplan-Meier analysis was used to estimate animal survival, and differences were analyzed using the logrank test. $P$-values $<0.001$, or $<0.05$, were considered significant.

\section{Results \\ Characterization of curcumin-bearing PLGA microparticles and microcells}

Sizing of prepared microcells was performed using a NANOPHOX analyzer (Sympatec GmbH, ClausthalZellerfeld, Germany). We further observed curcuminbearing PLGA microparticles, co-entrapped in PC-based microcells (of in-house preparation), of size $810 \pm 188 \mathrm{~nm}$ (Figure 2A and B). The zeta potential of the microcells was $-82.6 \pm 2.3 \mathrm{mV}$. Incubation of calcein-loaded microcells resulted in punctate fluorescence, suggesting payload uptake activity (Figure 2C). PLGA microparticles showed 17\% release of curcumin in 48 hours, which increased very slowly with time. In curcumin-bearing microcells, the release was much more sustained, by comparison. After 48 hours, there was $4 \%$ release of total content, which increased to $16 \%$ after 168 hours (Figure 2D). Curcumin-bearing PLGA microparticles followed an "initial burst" release pattern, whereas microcells provided a sustained release of encapsulated curcumin, which increased gradually during an extended period (Figure 2D).

\section{Toxicity test}

In vitro toxicity

Various newly-developed curcumin formulations were evaluated for in vitro toxicity using a RBC lysis test. Figure 3 shows the extent of cell lysis induced by various curcumin-based formulations. The complete (100\%) lysis of RBCs caused by Triton-X-100 was considered to be total lysis. The lytic abilities of empty microparticles and microcells were also examined. As shown in Figure 3, curcumin-bearing PLGA microparticle and microcells caused negligible lysis of erythrocytes, compared against free-form curcumin.

\section{In vivo toxicity}

In vivo toxicity of different curcumin-based formulations was examined by estimation of hepatic and renal function parameters. Animals were treated with various curcumin dosages (as described in Materials and methods), then serum was 
A

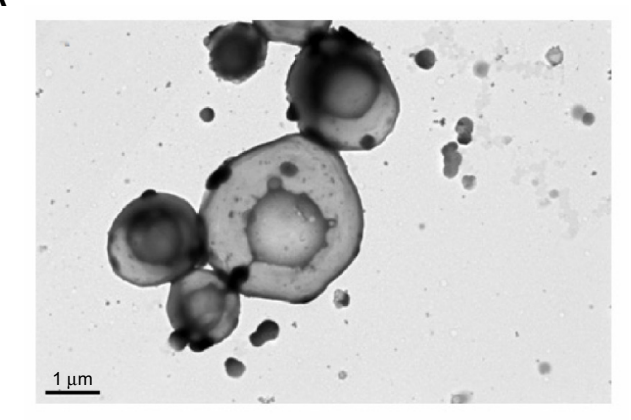

C

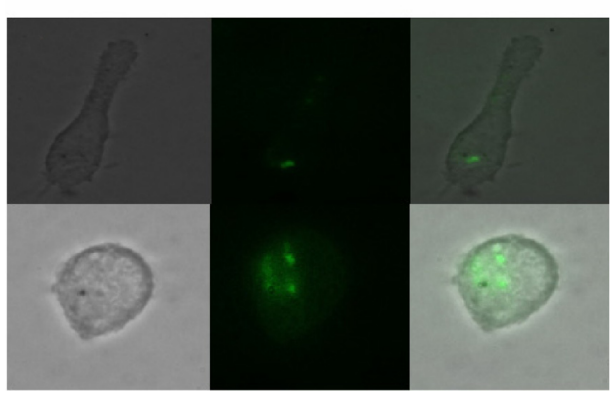

B

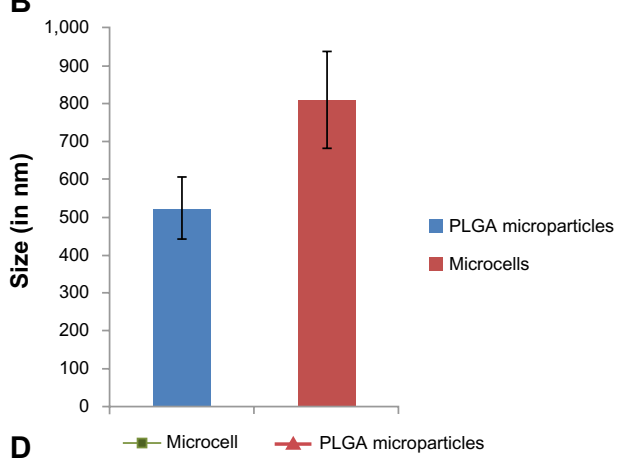

D

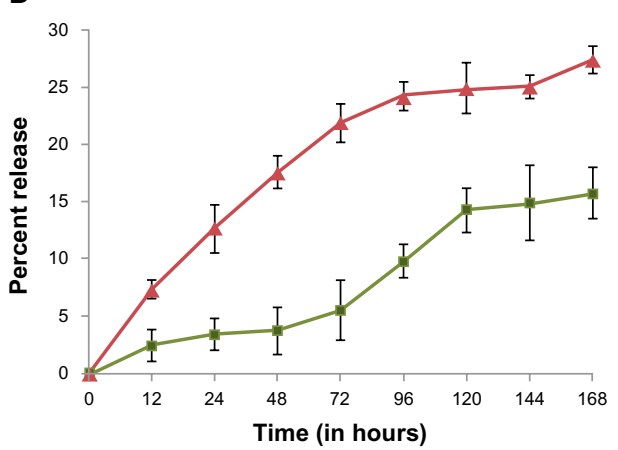

Figure 2 Characterization of curcumin-bearing microcells.

Notes: Size characterization of microcells using (A) transmission electron microscopy, and (B) NANOPHOX size analysis. (C) Uptake of calcein-loaded microcells by liver cancer cell line HepG2, as studied using fluorescence microscopy. (D) Release kinetics of curcumin from microcells and PLGA microparticles in 20 mM PBS (pH: 7.4) at $37^{\circ} \mathrm{C}$, studied using HPLC. The data represented here are the means of three different experiments, with standard deviations.

Abbreviations: PLGA, poly(lactic-co-glycolic acid); PBS, phosphate buffered saline; HPLC, high-performance liquid chromatography.

isolated for the estimation of levels of creatinine and ALP. Untreated animals served as a control for the comparison study. As shown in Table 1, curcumin-based formulations did not induce toxicity in the kidney and liver in the treated animals.

\section{MTT assay}

Figure 4 shows the effects of different concentrations of various curcumin formulations on HepG2 cell viability, in culture. Treatment with various concentrations of curcumin for 72 hours markedly attenuated the basal proliferation

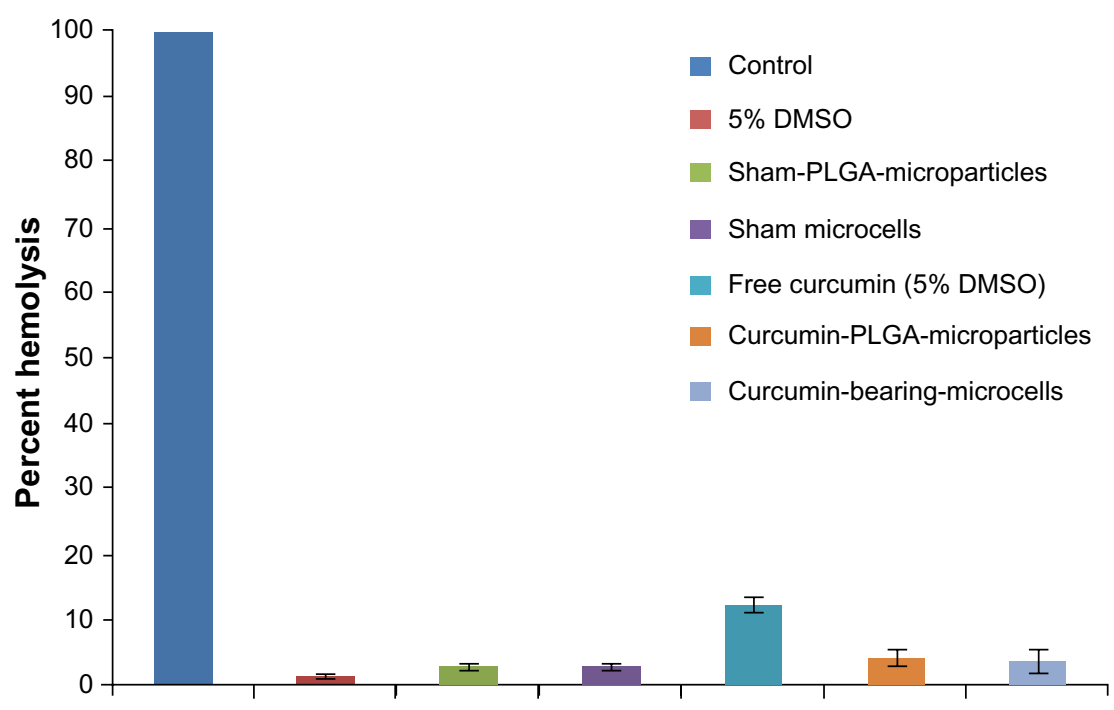

Figure 3 Erythrocyte lysis test.

Notes: In vitro toxicity was measured by erythrocyte lysis, induced by various curcumin formulations. Hemolysis testing was performed. The data represented here are the means of three different experiments, with standard deviations.

Abbreviations: DMSO, dimethyl sulfoxide; PLGA, poly(lactic-co-glycolic acid). 
Table I Concentrations of creatinine, ALP, AST, and ALT in plasma of animals treated with curcumin formulations

\begin{tabular}{lllll}
\hline Group & Creatinine $(\mathbf{m g} \%)$ & ALP (IU/L) & AST (IU/L) & ALT (IU/L) \\
\hline Control & $0.27 \pm 0.052$ & $32.23 \pm 2.10$ & $39.00 \pm 2.60$ & $37.90 \pm 1.20$ \\
Sham PLGA microparticles & $0.30 \pm 0.28$ & $38.42 \pm 1.46$ & $41.73 \pm 7.80$ & $39.82 \pm 2.33$ \\
Sham microcells & $0.24 \pm 0.034$ & $33.82 \pm 3.40$ & $38.12 \pm 3.24$ & $36.90 \pm 2.87$ \\
Free curcumin $(50 \mathrm{mg} / \mathrm{kg})$ & $0.36 \pm 0.038$ & $42.39 \pm 1.29$ & $47.71 \pm 7.45$ & $43.55 \pm 7.45$ \\
Curcumin PLGA microparticles (50 mg/kg) & $0.28 \pm 0.32$ & $35.12 \pm 2.42$ & $43.21 \pm 1.12$ & $40.45 \pm 3.12$ \\
Curcumin bearing microcells (50 mg/kg) & $0.22 \pm 0.011$ & $36.65 \pm 2.28$ & $40.82 \pm 4.21$ & $38.90 \pm 2.18$ \\
\hline
\end{tabular}

Notes: Creatinine: free curcumin versus curcumin PLGA microparticles, $P<0.00$ I; free curcumin versus curcumin-loaded microcells, $P<0.00$ I. ALP: free curcumin versus curcumin PLGA microparticles, $P<0.00$ I; free curcumin versus curcumin-loaded microcells, $P<0.00$ I. AST: free curcumin versus curcumin PLGA microparticles, $P<0.00$ I; free curcumin versus curcumin-loaded microcells, $P<0.00 \mathrm{I}$. ALT: free curcumin versus curcumin PLGA microparticles, $P<0.00 \mathrm{I}$; free curcumin versus curcumin loaded microcells, $P<0.001$.

Abbreviations: ALP, alkaline phosphatase; PLGA, poly(lactic-co-glycolic acid); AST, aspartate aminotransferase; ALT, alanine aminotransferase.

of HepG2. The survival of the HepG2 cell line was inversely correlated with curcumin concentration, indicating a dosedependent inhibitory effect. Median inhibitory concentration $\left(\mathrm{IC}_{50}\right)$ was calculated as $8.1 \pm 0.04 \mu \mathrm{M}$, for curcumin bearing microcells, and $10.8 \pm 1.5 \mu \mathrm{M}$, for PLGA microparticles.

\section{Biodistribution of curcumin}

There have been numerous studies reported about curcumin formulations, their development, and in vitro efficacy, but they have lacked information regarding the biodistribution of curcumin. ${ }^{27,28}$ We developed curcumin-based PLGA microparticles, and further co-encapsulated them in PC liposomes, with the aim of increasing the bioavailability of curcumin, which should improve anticancer efficacy.
In groups treated with free-form curcumin, as shown in Figure 5A, liver tissue had a significantly high concentration of curcumin at 2 hours post-injection. There was rapid elimination of the drug; after 24 hours, no detectable amount was found in the liver tissue. In the case of PLGA microparticle-treated animals, a lesser amount of curcumin was detected initially in the liver, which increased during the 12 hours post-injection. Subsequently, its concentration reduced, but was still detectable at 24 hours post-injection. Interestingly, we observed a constantly increasing concentration of curcumin in the livers of microcell-treated animals. Initially there was $39.65 \mu \mathrm{g} / \mathrm{g}$ of curcumin in liver tissue which increased to $78.8 \mu \mathrm{g} / \mathrm{g}$ at 72 hours postinjection.

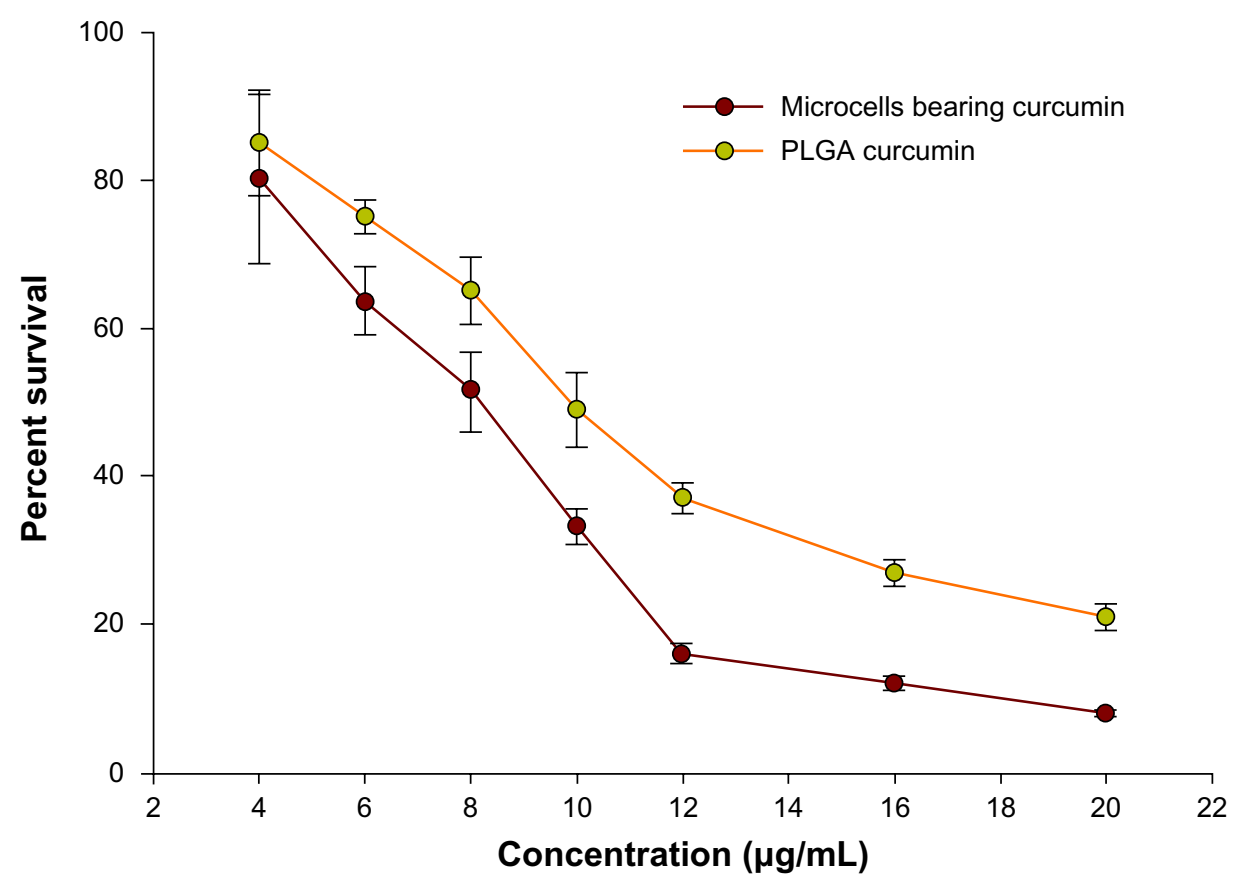

Figure 4 Effects of curcumin-loaded microcells and PLGA microparticles on the viability of HepG2 cells, as determined by MTT assay.

Note: The values for each concentration tested represent the average (mean, with standard deviation) from eight replicate wells, and are representative of three separate experiments.

Abbreviation: PLGA, poly(lactic-co-glycolic acid). 


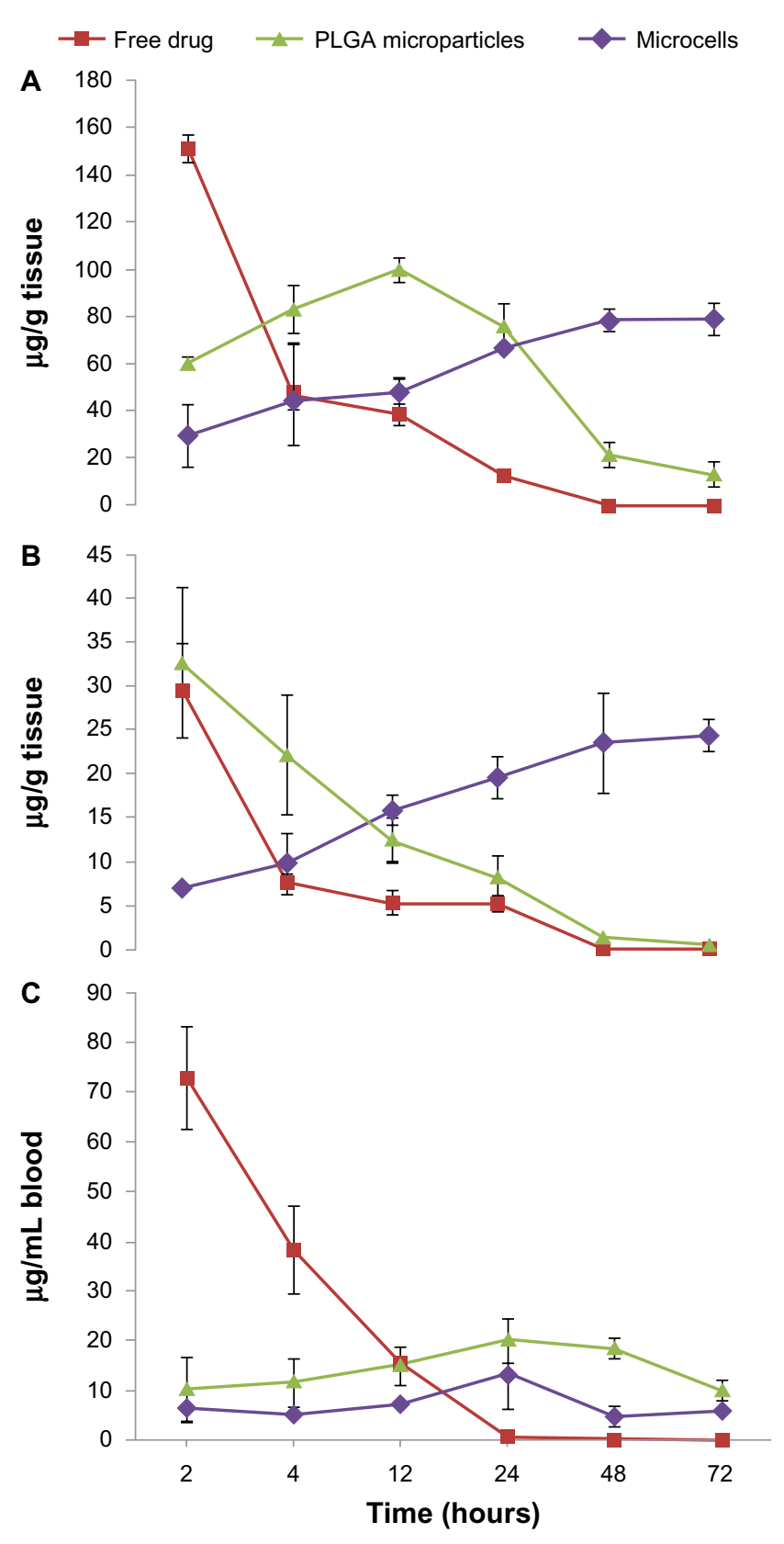

Figure 5 Biodistribution of curcumin from various curcumin formulations in various organs and systemic circulation of treated animals.

Notes: (A) Liver, (B) Kidney, and (C) blood. Curcumin distribution was analyzed for a period of 72 hours, as described in Materials and methods.

Abbreviation: PLGA, poly(lactic-co-glycolic acid).

Curcumin biodistribution was also examined in kidneys of treated animals. As shown in Figure 5B, the free-form curcumin-treated group had $29.5 \mu \mathrm{g} / \mathrm{g}$ curcumin in kidney tissue at 2 hours post-injection. Its concentration decreased further; only $5.21 \mu \mathrm{g} / \mathrm{g}$ was detected after 24 hours. PLGA microparticle-treated animals had $32.61 \mu \mathrm{g} / \mathrm{g}$ of curcumin in kidney tissue initially, which decreased further, but the concentration was still detectable after 72 hours $(0.38 \mu \mathrm{g} / \mathrm{g})$. The microcell-treated group showed a pattern of increasing curcumin concentration: $7.08 \mu \mathrm{g} / \mathrm{g}$ curcumin in kidney tissue at starting point, which increased to $24.42 \mu \mathrm{g} / \mathrm{g}$ at 48 hours post-injection.

We also examined the curcumin content of serum in groups of animals treated with various concentrations of different curcumin formulations (Figure 5C). After administration of free-form curcumin, its concentration in serum was very high at 2 hours post-injection. It then declined very quickly, and could not be detected after 24 hours post-treatment. PLGA microparticles and microcells did not release significant amounts of curcumin initially; its concentration increased slowly. Both groups had higher curcumin concentrations at 24 hours post-injection $(3.27 \mu \mathrm{g} / \mathrm{g}$ and $19.99 \mu \mathrm{g} / \mathrm{g}$ curcumin in serum, for microparticles and microcells, respectively). After 24 hours curcumin levels declined in both groups.

\section{Curcumin-loaded PLGA microparticles and microcells mediate downregulation of liver enzymes in treated animals}

We measured the activity of some important liver enzymes in the curcumin-treated groups. ALP activity decreased significantly after treatment with curcumin-bearing microcells, compared against free-form curcumin (microcells versus free-form curcumin: $P<0.01$ ). The curcumin-loaded PLGA microparticle-treated group showed a low level of ALP, which was not significant (curcumin-loaded PLGA microparticles versus free-form curcumin: $P<0.07$ ) (Figure 6A).

ASP activity was measured in the different experimental groups. As shown in Figure 6B, ASP activity was significantly decreased in both curcumin-bearing microcell- and PLGA microparticle-treated groups, compared to the freeform curcumin-treated group (microcells versus free-form curcumin: $P<0.05$; PLGA microparticles versus free-form curcumin: $P<0.05$ ). We also examined the level of GGT in the different treatment groups. Although curcuminbearing microcell- and PLGA microparticle-treated groups showed decreased levels of GGT, compared to the free-form curcumin-treated group, the differences were not significant (Figure 6C).

\section{Curcumin-loaded PLGA microparticles and microcells downregulate TNF- $\alpha$ level in treated animals}

Curcumin modulates TNF- $\alpha$-induced signaling, and acts as an inhibitor of TNF expression. ${ }^{29}$ In our study, we measured TNF- $\alpha$ levels in the different treatment groups. Our results 


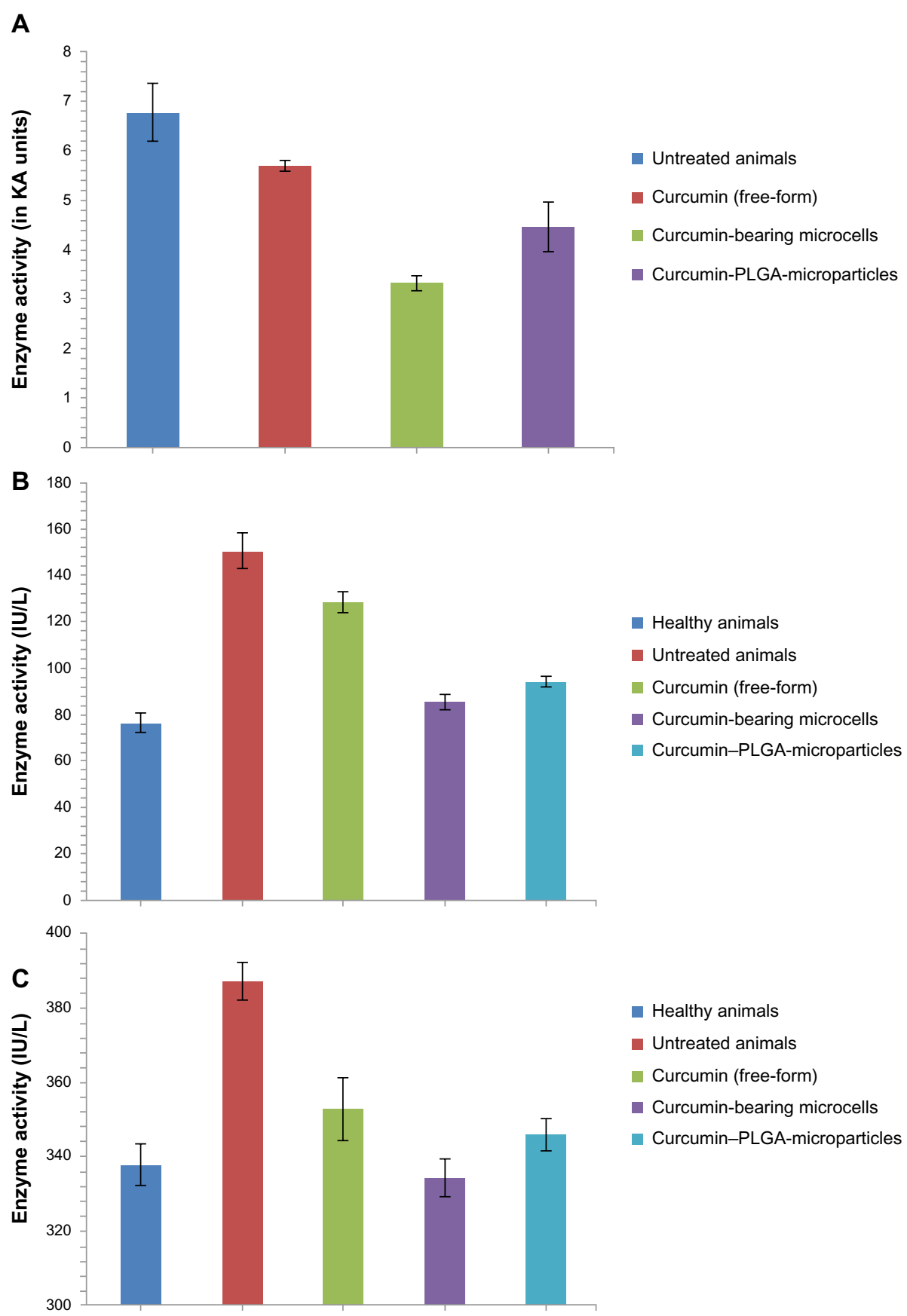

Figure 6 Liver enzyme levels in animals treated with various curcumin formulations.

Notes: Liver function enzyme activities were measured. The data represented here are means of three different experiments, with standard deviation. (A) ALP: microcells versus free curcumin, $P<0.0$ I; curcumin PLGA microparticles versus free curcumin, $P<0.07$. (B) AST: microcells versus free curcumin, $P<0.05$; curcumin PLGA-microparticle versus free curcumin, $P<0.05$. (C) GGT microcells versus free curcumin.

Abbreviations: PLGA, poly(lactic-co-glycolic acid); ALP, alkaline phosphatase; AST, aspartate aminotransferase; GGT, gamma-glutamyltransferase.

showed that both curcumin-bearing microcells and PLGA microparticles downregulate TNF- $\alpha$ expression. Although free-form curcumin also downregulated TNF- $\alpha$ expression, this effect was not as great as in the microcell- and microparticle-treated groups (PLGA microparticles versus free-form curcumin: $P<0.05$; microcells versus free-form curcumin: $P<0.05$ ) (Figure 7).

\section{Increased survival of curcumin-bearing PLGA microparticle- and microcell- treated animals}

We also monitored the survival of animals treated with various curcumin formulations for a period of 12 weeks. PLGA, with a 50:50 molar ratio of lactide to glycolide provides very prolonged, sustained release of entrapped molecules; its complete 


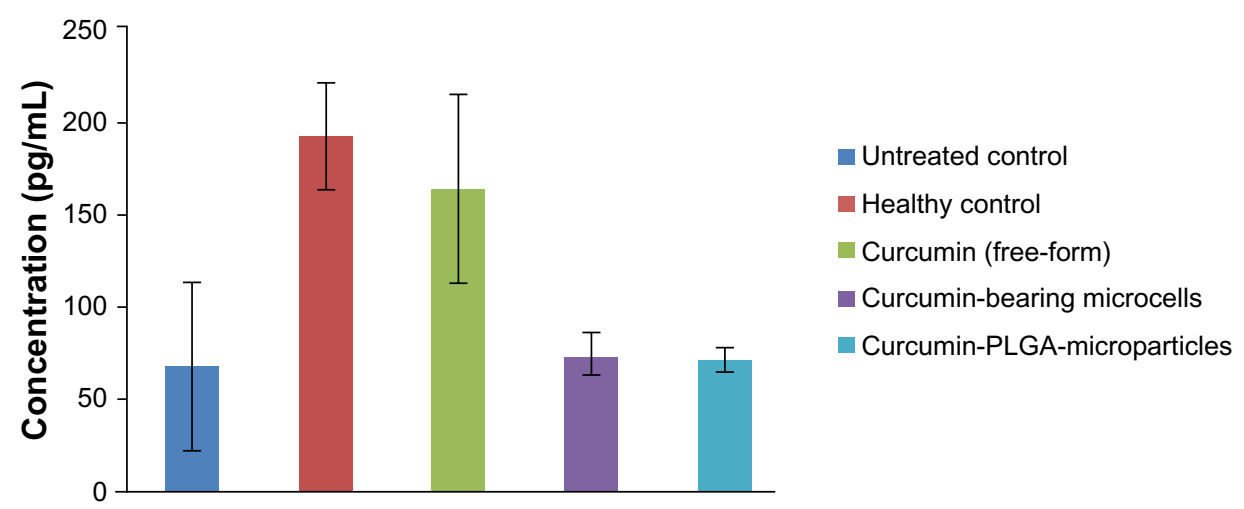

Figure 7 TNF- $\alpha$ expression profile in animals treated with various curcumin formulations.

Notes: TNF- $\alpha$ levels were measured in plasma. The data represented here are means of three different experiments, with standard deviations. Microcells versus free curcumin: $P<0.05$; curcumin PLGA microparticles versus free curcumin: $P<0.05$; microcells versus curcumin $P L G A$ microparticles: $P$ not significant.

Abbreviations: TNF- $\alpha$, tumor necrosis factor alpha; PLGA, poly(lactic-co-glycolic acid).

degradation requires 1-2 months. Although PLGA microparticles facilitated the release of entrapped curcumin for a longer period than with free-form curcumin treatment, this period was still shorter than in microcell-treated animals. A sustained release pattern of entrapped curcumin increases curcumins bioavailability, thus enhancing its efficacy. Our results show that the curcumin-bearing microcell-treated group had the greatest survival (80\%), followed by PLGA microparticle treatment group (70\%), while the free-form curcumin had only $20 \%$ survival (microcells versus free-form curcumin: $P<0.001$; PLGA microparticles versus free-form curcumin: $P<0.001)$ (Figure 8). No animals survived in the untreated, sham microcell, and sham PLGA microparticle groups after week 9.

\section{Histopathological analysis}

Compared against healthy control animals, the untreated group revealed a significant inductive effect of the carcinogen upon liver tissue. The free-form curcumin group showed cancer regression, but was associated with poorly preserved hepatocellular architecture. The curcuminbearing microparticles group showed only a mild effect. But, the microcell-encapsulated curcumin group demonstrated moderate therapeutic effect. The sham PLGA microparticle and sham microcell groups showed the same observations as the untreated group. Thus, not taking other factors into account, curcumin-bearing microcells showed the most marked recovery, followed by curcumin-loaded PLGA microparticles, then the free-form of the compound (Figure 9).

\section{Western blot analysis of apoptotic molecules}

The anticancer efficacy of various curcumin formulations was assessed using Western blot profiling of various apoptotic

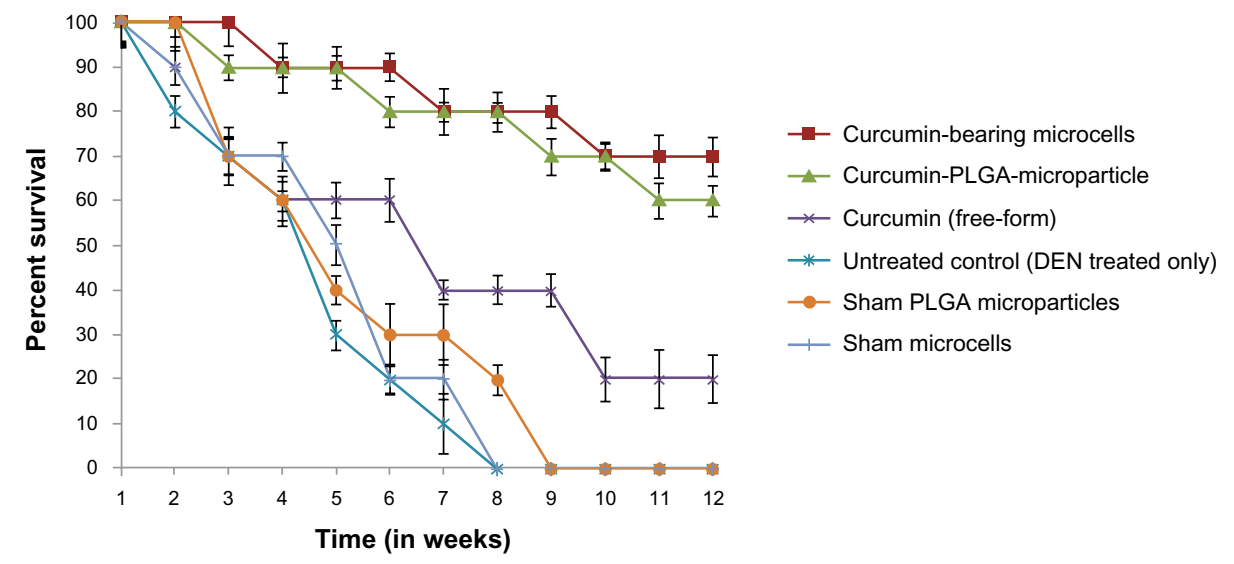

Figure 8 Survival graph for different curcumin formulations in different experimental groups.

Notes: Survival was monitored twice-daily for a period of 12 weeks. Each group contained ten animals. The data represented here are means of three different experiments, with standard deviations. Microcells versus free curcumin: $P<0.005$; curcumin PLGA microparticles versus free curcumin: $P<0.005$; microcells versus curcumin PLGA microparticles: $P$ not significant.

Abbreviations: PLGA, poly(lactic-co-glycolic acid); DEN, diethylnitrosamine. 


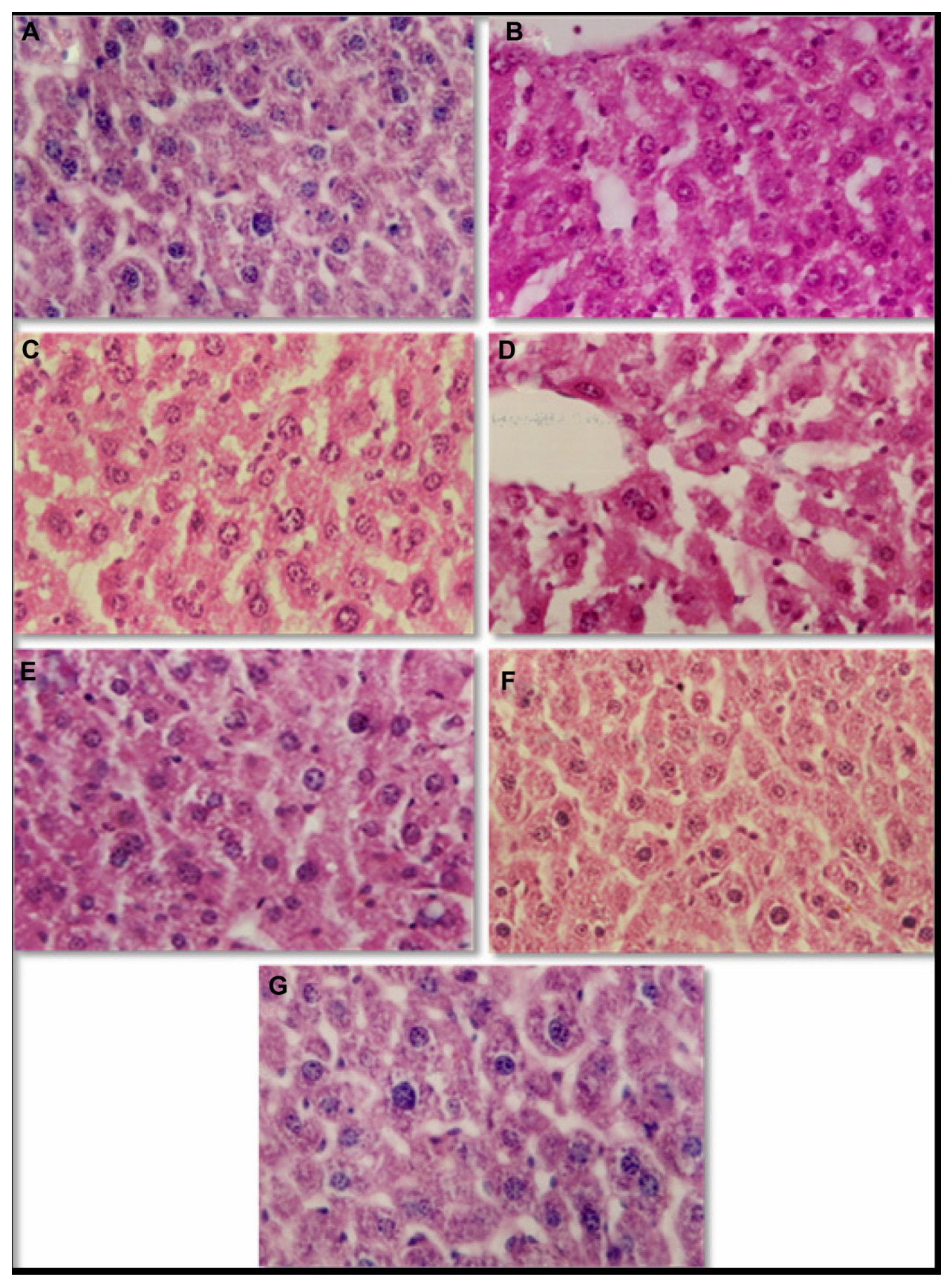

Figure 9 Histological analysis of various curcumin-treated groups.

Notes: (A) Healthy control: liver cells showed normal cords of hepatocytes and sinusoids. (B) Untreated group: showed hypercellularity, cellular nuclear polymorphism, and overtly hyperchromatic, large nuclei with increased nuclear cytoplasmic ratio. (C) Curcumin-bearing microcells: hepatic cords and sinusoids appear very similar to the healthy control. (D) Curcumin-bearing PLGA microparticles: showed increased cellularity, hyperchromatic nuclei, and altered hepatocellular contour, with distorted sinusoids. (E) Free curcumin: showed reduction in nuclear cytoplasmic ratio, poorly maintained hepatocellular contour, and dilated sinusoids. (F and G) Sham microcells and PLGA microparticles: showed poorly-maintained architecture of hepatocytes, with cancer growth very similar to the untreated control.

Abbreviation: PLGA, poly(lactic-co-glycolic acid).

molecules in the different experimental groups. As shown in Figure 10, curcumin-bearing microcells and PLGA microparticles had more prominent effects on proapoptotic molecules than did free-form curcumin, which had a very low expression profile. Sham microcells and sham PLGA microparticles had the same level of expression as in the untreated group (data not shown). The data are suggestive of liver cancer regression in both curcumin-bearing microcell- and PLGA microparticle-treated animals.

\section{Discussion}

Recent advancements in the field of drug delivery have led to the development of novel, biocompatible, and biodegradable drug delivery systems that are capable of targeting cells 


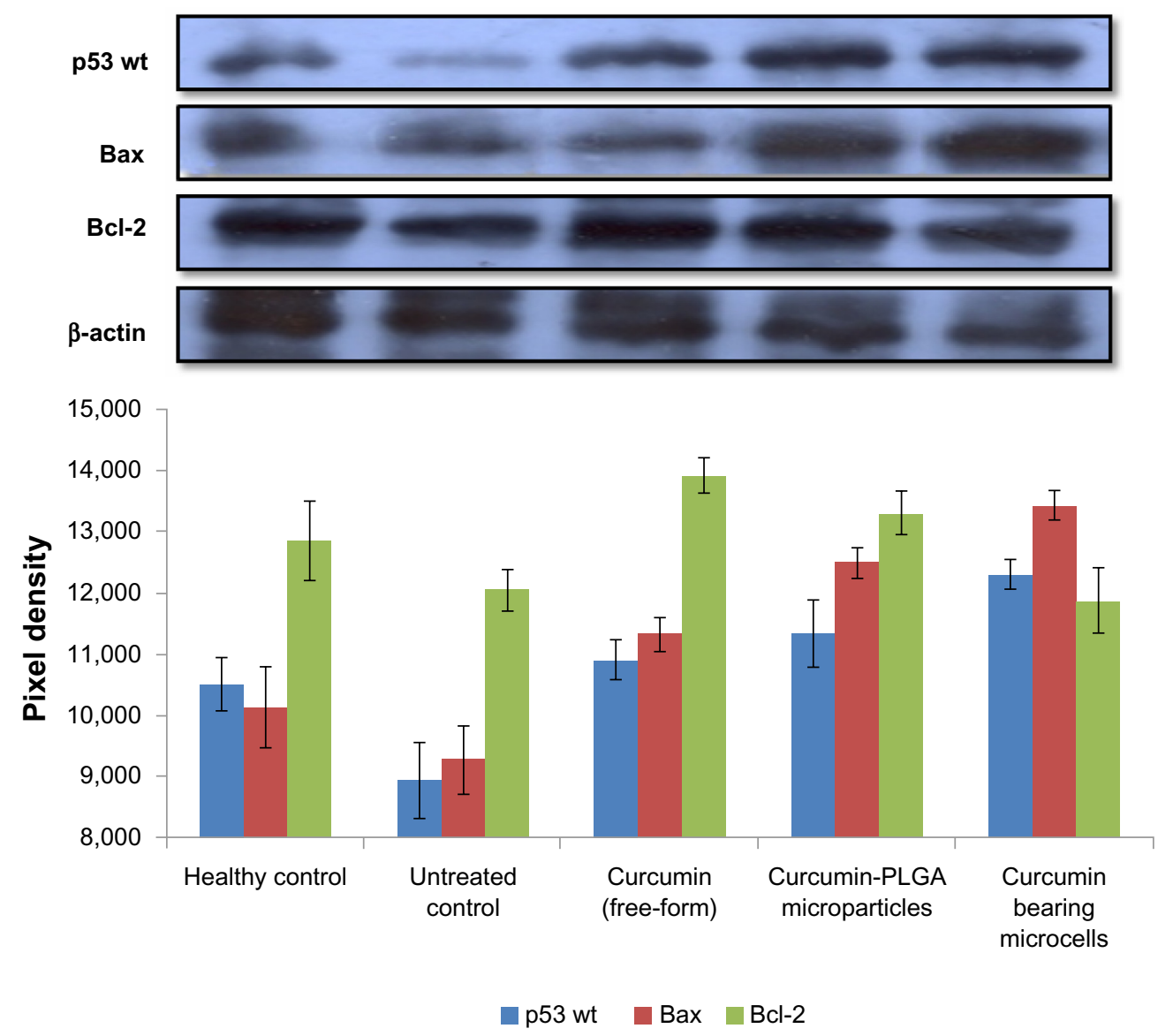

Figure 10 Expression profiles of apoptotic molecules in different experimental groups.

Note: Data acquired using Western blot assay of p53 wt, Bax, and Bcl-2 in liver extract from mice treated with various curcumin formulations.

Abbreviations: Bcl-2, B-cell lymphoma-2; Bax, Bcl-2 associated X protein; PLGA, poly(lactic-co-glycolic acid); wt, wild type.

and tissues in a specific fashion, without affecting adjacent cell types. They can be employed for the active, and passive, targeting of various bioactive molecules. In the past decade, there have been numerous efforts to evaluate the potency of curcumin against human cancer cell lines. ${ }^{22,30-32}$ Despite exhibiting strong anticancer activity in vitro, curcumin's poor absorption and rapid elimination from systemic circulation hinders its activity in vivo. In a quest to develop a nanocarrier for the delivery of (hydrophobic) curcumin, we prepared dual-core microcells, consisting of PLGA microparticles, further co-entrapped in egg PC liposomes. Electron microscopic study clearly showed a dual-core microcell morphology (or "texture") (Figure 2A and B). Microcells successfully delivered their content into the cytosol of hosts, as demonstrated in the uptake of calcein by HepG2 cells (Figure 2C). Microcells formed with this dual coating system demonstrated sustained release of encapsulated material (Figure 2D). As shown in release kinetic studies (performed at $37^{\circ} \mathrm{C}$ ), the co-entrapment of the PLGA microparticle in a dual-core microcell delivery system further regulated release, exhibiting a time-dependent release pattern of entrapped curcumin molecules. The "initial burst" release pattern of the PLGA microparticle can be correlated with its loading of surface-adsorbed curcumin.

It is a prerequisite to evaluate the toxicity of any novel formulation before introducing it into the in vivo system. To this end, our toxicity studies demonstrated that curcumin-bearing microcells and PLGA microparticles were nontoxic to living cells, as revealed by in vitro RBC lysis testing (Figure 3). Furthermore, the LFT and renal function test parameters studied in vivo suggest that freeform curcumin, curcumin-bearing microcells, and PLGA microparticles with entrapped curcumin did not possess any intrinsic toxicity (Table 1). Our study ascertained that the curcumin-bearing microcell formulation is not only safe, and free of any toxicity constraints, but also increases the bioavailability of curcumin. MTT assay data showed that curcumin-loaded microcells, and PLGA microparticles, exhibited notable antiproliferative activity toward HepG2 cells (Figure 4). 
Before translating microcell-based curcumin formulations for use against HCC to animal models, we examined curcumins biodistribution in different vital organs. In the free-form curcumin-treated group, negligible amounts of curcumin were detected in liver and kidney tissues after 24 hours posttreatment, while a very low serum concentration was observed in treated animals (Figure 5C). In the PLGA microparticletreated group, the concentration of curcumin was relatively higher in the different organs. Curcumin-bearing microcells maintained a sustained release of curcumin for up to 48 hours (Figure 5A and B). However, the serum level of curcumin was same in both PLGA microparticle- and microcell-based delivery systems (Figure 5C).

To establish the anticancer properties of our in-house preparation of curcumin-bearing microcells, we induced HCC, using DEN, in model animals. Liver enzyme levels (ALP, aspartate aminotransferase, and GGT) in treated animals were used as markers of the establishment of cancer, and to study the efficacy of our formulations. PLGA microparticles with entrapped curcumin, and microcellbased formulations, were found to significantly reduce liver enzymes, compared to free-form curcumin (Figure 6). The most significant reductions were observed in animals treated with PLGA microparticles co-entrapped in microcells. Sham microcells and sham PLGA microparticles had no effect on liver enzyme levels, which behaved in a manner similar to the untreated group (data not shown). Curcumin inhibits activation of the protein complex NF- $\mathrm{\kappa B}$, which, in turn, reduces host expression inflammatory cytokines, including TNF- $\alpha$. TNF- $\alpha$ plays an important role in tumor cell survival, differentiation, and metastasis. Our results suggest that curcumin-bearing microcells inhibit TNF- $\alpha$ expression the most, followed by PLGA microparticles; free-form curcumin had only a very mild effect (Figure 7). The control formulations (sham delivery systems) were unable to downregulate TNF- $\alpha$ expression (data not shown).

Survival data showed a significant reduction in animal mortality. The curcumin-bearing microcell-treated group had $70 \%$ survival; the PLGA microparticle-treated group had $60 \%$ survival. By contrast, the free-form curcumintreated group had only $20 \%$ survival (Figure 8 ). All animals treated with sham microcells or sham PLGA microparticles did not survive beyond 9 weeks.

Histological analysis showed hypercellularity and overtly hyperchromatic large nuclei in the untreated group. Interestingly, curcumin-bearing microcells facilitated quick recovery, compared to healthy animals. Treatment with curcuminbearing PLGA microparticles resulted in mild recovery, where increased cellularity, hyperchromatic nuclei, and distorted sinusoids, were observed. Among various curcumin formulation-treated groups, free-form curcumin was the least effective for the treatment of cancer (Figure 9E). The control groups also failed to demonstrate any remarkable recovery of liver cells (Figure 9).

Mutation in the tumor suppressor gene p53 is a wellknown cause of the upregulated growth of cells. Mutation in the p53 gene results in its functional inactivation, loss of its genomic integrity, and its escape from apoptosis. ${ }^{33}$ Proteins of the Bcl-2 family play an important role in apoptosis, maintaining balance in the cell. Bax, is a dominant inhibitor of Bcl-2, and induces apoptosis through its overexpression, which damage mitochondria. Furthermore, Bax releases apoptosis mediators and cytochrome $\mathrm{C}$; which ultimately leads to cell death. ${ }^{34}$ With the aim of examining apoptosis, we evaluated the expression of gene $p 53$ wildtype (wt), and Bax, in liver tissue extract from the different curcumin formulation-treated groups. Western blot analysis of proapoptotic molecules ( $p 53 w \mathrm{t}$ and Bax) revealed that curcumin-bearing microcells induced their expression the most, followed by PLGA microparticles. Free-form curcumin was found to have only a very mild effect on expression of proapoptotic molecules. Bax expression was upregulated in both PLGA microparticle- and microcell-treated groups (Figure 10). Interestingly, Bcl-2 expression was very low in microcell- and PLGA microparticle-treated groups; it was overexpressed in free-form curcumin-treated animals. In concordance with survival data and histological studies, our Western blot profile of apoptotic molecules is suggestive of superior efficacy of curcumin-bearing microcells. Sham microcells and PLGA microparticles had no effect on the expression of $\mathrm{p} 53 \mathrm{wt}$, or of Bax.

Therapeutic strategies based on dual-core delivery systems hold great promise, due to their ability to release entrapped anticancer drugs in a sustained manner, and also to influence cell cycle checkpoints, to ensure the effective killing of cancer cells. The approach we have introduced provides an experimental framework to modulate various apoptotic factors in a desired manner. Although the dual-core delivery system has proved to be effective against $\mathrm{HCC}$ (through passive delivery to the liver), the formulation can be made more impressive by targeting delivery to desired sites.

\section{Conclusion}

The data presented in this study suggest that curcumin's bioavailability increases with its encapsulation in PLGA microparticles that are further co-entrapped in PC microcells. A sustained 
release of drug payload to the liver improves the therapeutic index of curcumin, assisting in the reduction of HCC. Also, it can be concluded that microcells are more effective than PLGA microparticles. The difference in the chemotherapeutic efficacy of the two systems can be correlated with sustained, slow delivery of the drug to systemic circulation.

\section{Disclosure}

The authors report no conflict of interest in this work.

\section{References}

1. Parkin DM, Pisani P, Ferlay J. Estimates of the worldwide incidence of 25 major cancers in 1990. Int J Cancer. 1999;80(6):827-841.

2. Simonetti RG, Liberati A, Angiolini C, Pagliaro L. Treatment of hepatocellular carcinoma: a systematic review of randomized controlled trials. Ann Oncol. 1997;8(2):117-136.

3. Shishodia S, Sethi G, Aggarwal BB. Curcumin: getting back to the roots. Ann NY Acad Sci. 2005;1056:206-217.

4. Inano $\mathrm{H}$, Onoda $\mathrm{M}$, Inafuku $\mathrm{N}$, et al. Chemoprevention by curcumin during the promotion stage of tumorigenesis of mammary gland in rats irradiated with gamma-rays. Carcinogenesis. 1999;20(6):1011-1018.

5. Chuang SE, Kuo ML, Hsu CH, et al. Curcumin-containing diet inhibits diethylnitrosamine-induced murine hepatocarcinogenesis. Carcinogenesis. 2000;21(2):331-335.

6. Singh SV, Hu X, Srivastava SK, et al. Mechanism of inhibition of benzo[a]pyrene-induced forestomach cancer in mice by dietary curcumin. Carcinogenesis. 1998;19(8):1357-1360.

7. Li N, Chen X, Liao J, et al. Inhibition of 7,12-dimethylbenz[a]anthracene (DMBA) induced oral carcinogenesis in hamsters by tea and curcumin. Carcinogenesis. 2002;23(8):1307-1313.

8. Kawamori T, Lubet R, Steele VE, et al. Chemopreventive effect of curcumin, a naturally occurring anti-inflammatory agent, during the promotion/progression stages of colon cancer. Cancer Res. 1999;59(3): 597-601.

9. Verma RK, Pandya S, Misra A. Loading and release of amphotericin-B from biodegradable poly(lactic-co-glycolic acid) nanoparticles. J Biomed Nanotechnol. 2011;7(1):118-120.

10. Pietzyk B, Henschke K. Degradation of phosphatidylcholine in liposomes containing carboplatin in dependence on composition and storage conditions. Int J Pharm. 2000;196(2):215-218.

11. Jain AK, Das M, Swarnakar NK, Jain S. Engineered PLGA nanoparticles: an emerging delivery tool in cancer therapeutics. Crit Rev Ther Drug Carrier Syst. 2011;28(1):1-45.

12. Riganti C, Voena C, Kopecka J, et al. Liposome-encapsulated doxorubicin reverses drug-resistance by inhibiting P-glycoprotein in human cancer cells. Mol Pharm. 2011;8(3):683-700.

13. Farazuddin M, Chauhan A, Khan RM, Owais M. Amoxicillin-bearing microparticles: potential in the treatment of Listeria monocytogenes infection in Swiss albino mice. Biosci Rep. 2011;31(4):265-272.

14. Jeffery H, Davis SS, O'Hagan DT. The preparation and characterization of PLGA microspheres: II. The entrapment of model protein using (water in oil) in water emulsion solvent evaporation technique. Pharm Res. 1993;10(3):362-368.

International Journal of Nanomedicine

\section{Publish your work in this journal}

The International Journal of Nanomedicine is an international, peerreviewed journal focusing on the application of nanotechnology in diagnostics, therapeutics, and drug delivery systems throughout the biomedical field. This journal is indexed on PubMed Central, MedLine, CAS, SciSearch ${ }^{\circledR}$, Current Contents ${ }^{\circledR} /$ Clinical Medicine,
15. Farazuddin M, Sharma B, Khan AA, Joshi B, Owais M. Anticancer efficacy of perillyl alcohol-bearing PLGA microparticles. Int $J$ Nanomedicine. 2012;7:35-47.

16. Khan MA, Nasti TH, Saima K, et al. Co-administration of immunomodulator tuftsin and liposomised nystatin can combat less susceptible Candida albicans infection in temporarily neutropenic mice. FEMS Immunol Med Microbiol. 2004;41(3):249-258.

17. Jayaprakasha GK, Rao LJM, Sakariah KK. Improved HPLC method for the determination of curcumin, demethoxycurcumin, and bisdemethoxycurcumin. J Agric Food Chem. 2002;50(13):3668-3672.

18. Khan MA, Syed FM, Nasti, et al. Use of tuftsin bearing nystatin liposomes against an isolate of Candida albicans showing less in vivo susceptibility to amphotericin B. J Drug Target. 2002;11(2):93-99.

19. Pitot HC, Barsness L, Goldsworthy T, Kitagawa T. Biochemical characterisation of stages of hepatocarcinogenesis after a single dose of diethylnitrosamine. Nature. 1978;271(5644):456-458.

20. Kuttan R, Bhanumathy P, Nirmala K, George MC. Potential anticancer activity of turmeric (Curcuma longa). Cancer Lett. 1985;29(2): 197-202.

21. Carr BI, Pancoska P, Branch RA. Significance of increased serum GGTP levels in HCC patients. Hepatogastroenterology. 2010;57(101): 869-874.

22. Aggarwal BB, Shishodia S. Molecular targets of dietary agents for prevention and therapy of cancer. Biochem Pharmacol. 2006;71(10): 1397-1421.

23. Chauhan A, Swaleha Z, Ahmad N, et al. Escheriosome mediated cytosolic delivery of Candida albicans cytosolic proteins induces enhanced cytotoxic $\mathrm{T}$ lymphocyte response and protective immunity. Vaccine. 2011;29(33):5424-5433.

24. Serpi R, Piispala J, Jarvilehto M, Vahakangas K. Thapsigargin has similar effect on $\mathrm{p} 53$ protein response to benzo(a)pyrene DNA adducts as TPA in mouse skin. Carcinogenesis. 1999;20(9):1755-1760.

25. Towbin H, Staehelin T, Gordon J. Electrophoretic transfer of proteins from polyacrylamide gels to nitrocellulose sheets: procedure and some applications. Proc Natl Acad Sci. 1979;76(9):4350-4354.

26. Lowry OH, Rosenbrough NK, Farr AL, Randall RJ. Protein measurement with the folin phenol reagent. J Biol Chem. 1951;193(1):265-275.

27. Bisht S, Feldmann G, Soni S, et al. Polymeric nanoparticle-encapsulated curcumin ("nanocurcumin"): a novel strategy for human cancer therapy. J Nanobiotechnology. 2007;5:3.

28. Li L, Braiteh FS, Kurzrock R. Liposome-encapsulated curcumin: in vitro and in vivo effects on proliferation, apoptosis, signaling, and angiogenesis. Cancer. 2005;104(6):1322-1331.

29. Aggarwal BB, Shishodia S, Takada Y, et al. TNF blockade: an inflammatory issue. Ernst Schering Res Found Workshop. 2006;56:161-186.

30. Duvoix A, Blasius R, Delhalle S, et al. Chemopreventive and therapeutic effects of curcumin. Cancer Lett. 2005;223(2):181-190.

31. Aggarwal BB, Kumar A, Bharti AC. Anticancer potential of curcumin: preclinical and clinical studies. Anticancer Res. 2003;23(1A): 363-398.

32. Choudhuri T, Pal S, Das T, Sa G. Curcumin selectively induces apoptosis in deregulated cyclin D1-expressed cells at G2 phase of cell cycle in a p53-dependent manner. J Biol Chem. 2005;280(20):20059-20068.

33. Soussi T. The 533 tumor suppressor gene: from molecular biology to clinical investigation. Ann NY Acad Sci. 2000;910:121-137.

34. Cory S, Huang CSD, Adams MJ. The Bcl-2 family: roles in cell survival and oncogenesis. Oncogene. 2003;22(53):8590-8607.

\section{Dovepress}

Journal Citation Reports/Science Edition, EMBase, Scopus and the Elsevier Bibliographic databases. The manuscript management system is completely online and includes a very quick and fair peer-review system, which is all easy to use. Visit http://www.dovepress.com/ testimonials.php to read real quotes from published authors. 